\title{
Retraction notice: Effect of pretreatment temperature on catalytic performance of the catalysts derived from cobalt carbonyl cluster in Fischer-Tropsch Synthesis
}

\author{
O.Byambasuren $^{1 *}$, D.Ulziibayar ${ }^{2}$, D.Chiibaatar ${ }^{2}$ \\ 1Department of Research and Innovation, Mongolian National University, Ulaanbaatar, \\ ${ }^{2}$ School of Mining and Engineering, Mongolian National University,
}

ARTICLE INFO: Received: 29 Sep, 2016; Revised: 29 Nov, 2016 Accepted: 7 Dec, 2016

Copyright $\odot 2016$ Byambasuren O, et al. This is an open access article distributed under the Creative Commons Attribution 4.0 International License CC BY, which permits unrestricted use, distribution, and reproduction in any medium, provided the original work is properly cited.

\section{RETRACTION NOTICE}

On 3rd March 2018, the Editorial Board of the Mongolian Journal of Chemistry decided to retract this article entitled "Effect of pretreatment temperature on catalytic performance of the catalysts derived from cobalt carbonyl cluster in Fischer-Tropsch Synthesis" because of an authorship dispute. The article was originally published in Vol.17 No.43 2016 pp.38-41.

DOI: http://dx.doi.org/10.5564/mjc.v17i43.745 